\title{
Regioselective One-pot Protection and Protection-glycosylation of Carbohydrates
}

\author{
Cheng-Chung Wang ${ }^{\star a}$, Medel Manuel L. Zulueta ${ }^{b}$, and Shang-Cheng Hung ${ }^{\star b}$
}

\begin{abstract}
Deciphering the roles and structure-activity relationships of carbohydrates in biological processes requires access to sugar molecules of confirmed structure and high purity. Chemical synthesis is one of the best ways to obtain such access. However, the synthesis of carbohydrates has long been impeded by two major challenges - the regioselective protection of the polyol moiety of each monosaccharide building block and the stereoselective glycosylation to produce oligosaccharides of desired length. Here, we review the development of the first regioselective protection-glycosylation and a revolutionary regioselective combinatorial one-pot protection of monosaccharides that can be used to differentiate the various hydroxy groups of monosaccharides with a vast array of orthogonal protective groups in one-pot procedures.
\end{abstract}

Keywords: Carbohydrate chemistry · Glycosylation · One-pot reactions · Protective groups · Regioselective etherification

\section{Introduction}

Carbohydrates play essential roles in biological processes ${ }^{1]}$ but their interactions with other biological agents at the molecular level are still unclear. In order to elucidate their physiological functions and structure-activity relationships, homogeneous and well-defined materials are indispensable. However, the isolation and purification of oligosaccharides and glycoconjugates from natural sources in adequate amount and purity are often impractical owing to their structural microheterogeneity. Chemical synthesis is therefore one of the most convenient ways to generate these biologically important compounds. The structural diversity that enables their complex functions in biological processes has retarded advances in their syntheses. The level as yet attained is still far behind the standardized acquisition protocols available for peptides and nucleotides.

For the syntheses of oligosaccharides, ${ }^{[2-4]}$ the regio- and stereoselectivity as well as the eventual functional group modification of the target molecules have

${ }^{*}$ Correspondence: Dr. C.-C. Wanga,

Prof. Dr. S.-C. Hung ${ }^{b}$

Tel.: + 886227871279

Fax: + 886227899931

E-mail: wangcc@chem.sinica.edu.tw,

schung@gate.sinica.edu.tw

alnstitute of Chemistry

'Genomics Research Center

Academia Sinica

128, Section 2, Academia Road

115 Taipei, Taiwan

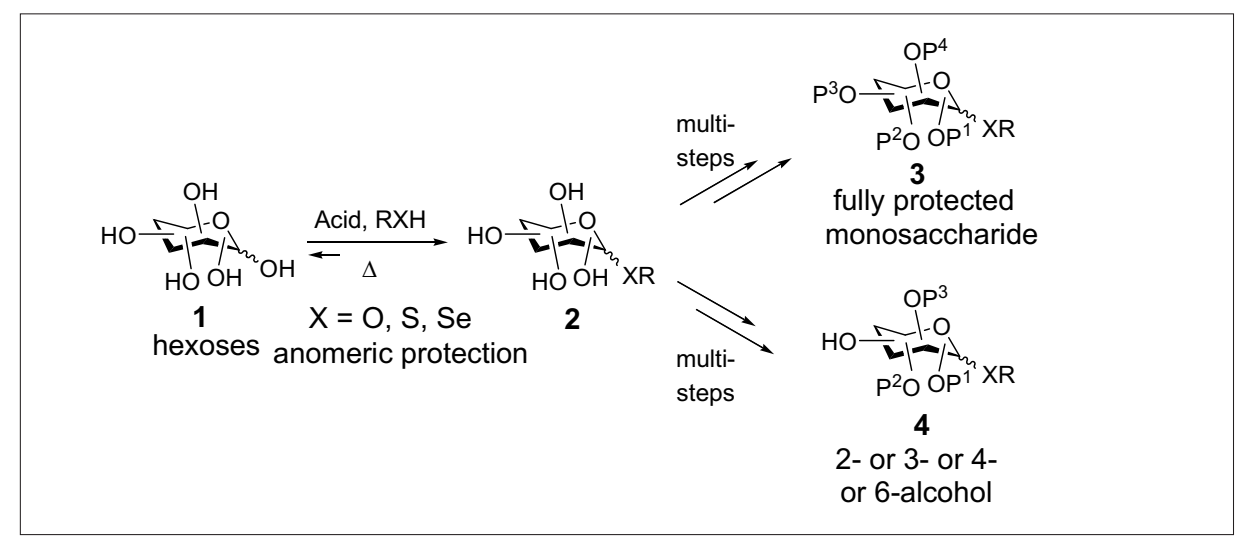

Fig. 1. Traditional method in monosaccharide protection.

to be taken into account. Therefore, the efficient preparation of various monosaccharide building blocks that comply with the target molecules and their rapid stereocontrolled assembly into long heterooligomers ${ }^{[5-17]}$ are the major challenges in oligosaccharide synthesis. Typical building block synthesis still entails laborious multistep protocols and requires tedious purifications of intermediates.

Two types of monosaccharide building blocks are necessary. One has a strategically exposed free hydroxyl group to serve as nucleophilic acceptor; the other contains a labile leaving group at the anomeric carbon to act as glycosyl donor in the ensuing glycosylation. Generally, the anomeric position of hexose $\mathbf{1}$ can be selectively protected by alcohols, thiols or selenols in an acid-catalyzed reaction to afford the corresponding hexopyranoside 2 (Fig. 1). ${ }^{[2,18]}$ The remaining hydroxyls, on the other hand, have nearly similar reactivities and further differentiations usually generate mixtures of regioisomers. Thus, the transformations of tetraols $\mathbf{2}$ into fully protected monosaccharides of type $\mathbf{3}$ or alcohols of type $\mathbf{4}$ with a free hydroxyl at either $\mathrm{C}(2), \mathrm{C}(3), \mathrm{C}(4)$, or $\mathrm{C}(6)$ are said to be tricky and require multiple protectiondeprotection sequences.

\section{One-pot Protection- Glycosylation of Monosaccharides}

In 2002, we found that the $\mathrm{Et}_{3} \mathrm{SiH}$ reductive etherification ${ }^{[19]}$ of glucose trimethylsilyl ether $\mathbf{5 a}$ or $\mathbf{5 b}$ with various aldehydes catalyzed by trimethylsilyl trifluoromethanesulfonate (TMSOTf) at -78 ${ }^{\circ} \mathrm{C}$ successfully distinguished $\mathrm{C}(2)$ and $\mathrm{C}(3)$ hydroxyl groups. Here, a single $\mathrm{O}(3)$ ether was obtained without hydrolyzing or opening the benzylidene acetal at $\mathrm{O}(4)$, $\mathrm{O}(6)$. After treatment with tetra- $n$-butylammonium fluoride (TBAF) to remove the trimethylsilyl (TMS) group at $\mathrm{O}(2)$, the corresponding 2-alcohols 6a1-6a5 and 6b1 were obtained in high yields, as sum- 
Table 1. TMSOTf-activated $\mathrm{Et}_{3} \mathrm{SiH}$-reductive $\mathrm{O}(3)$-etherification of $\mathbf{5 a}$ and $\mathbf{5 b}$ with a series of aldehydes.

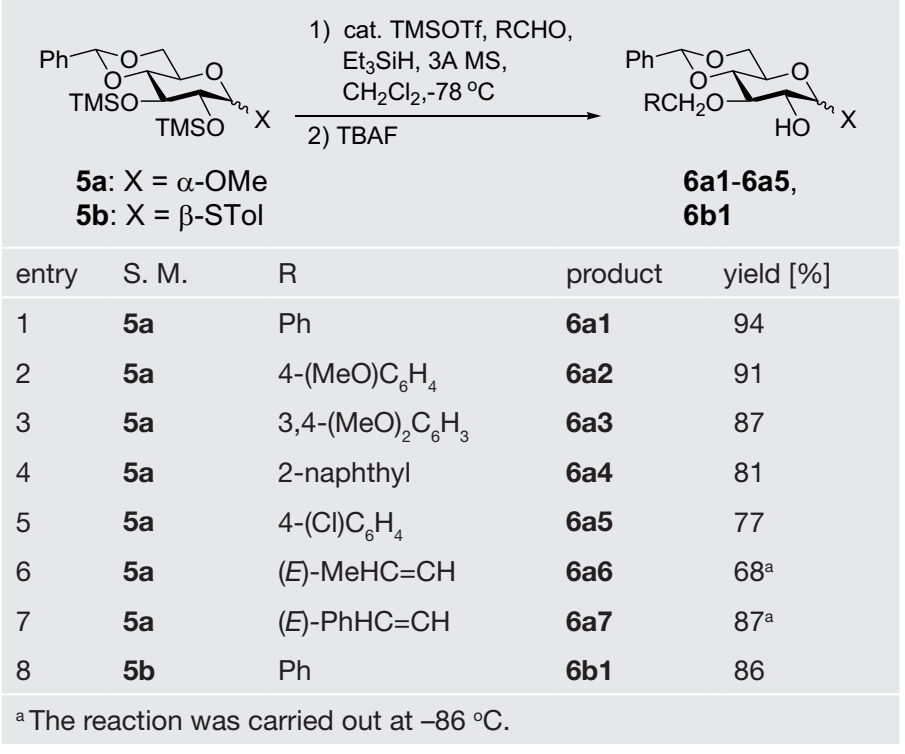

marized in Table 1. ${ }^{[20]}$ The lower reactivity of the $\mathrm{C}(2)$ versus $\mathrm{C}(3)$ hydroxyl group is believed to arise from the inductive effect of the two adjacent anomeric oxygen atoms (field effect) and the steric hindrance provided by the anomeric methoxy or $p$ methylphenyl thio group (toluenyl, Tol) and the O(3)-TMS etheral moiety. The regioselective etherifications of a series of $O$-trimethylsilylated pyranosides with different aldehydes were studied and are listed in Table 2. The transformations of 4,6- $O$-isopropylidene ketal 7, $\alpha$-allyl pyranoside 9 and $\alpha, \alpha^{\prime}$-trehalose derivative 11 similarly gave the corresponding $\mathrm{O}(3)$ Bn products 8, 10 and 12 in good yields and with complete regioselectivity (Table 2 , entries $1-3)$. The challenging $\mathrm{O}(6)$ benzylation of $\beta$-cyclodextrin ${ }^{[21]}$ was achieved from trimethylsilylated $\beta$-cyclodextrin 13 furnishing the corresponding $\mathrm{O}(6)-\mathrm{Bn}$ compound $\mathbf{1 4}$ in $62 \%$ yield (Table 2 , entry 4). Differentiation of $\mathrm{O}(2)$ and $\mathrm{O}(6)$ hydroxyl groups of the galactopyranosides 15 and 19 using the same conditions was also effective, and gave the corresponding $\mathrm{O}(6)$-etherified compounds $\mathbf{1 6}-\mathbf{1 8}$ and $\mathbf{2 0}$ in excellent yields and selectivity (Table 2, entries 5-8), while standard Williamson's condition (sodium hydride and benzyl bromide) gave the corresponding $\mathrm{O}(2)$-benzylated compounds as major products. ${ }^{[22]}$

Since coupling reactions of sugars often employ TMSOTf as promoter, we inferred that further $\mathrm{O}(2)$ glycosylation reaction to prepare $1 \rightarrow 2$ linked disaccharides can be continued after the reductive etherification in the same pot. This was indeed the case for perbenzylated D-galacto- (21), D-manno- (22), L-fuco- (25) or D-glucopyranosyl trichloroacetimidate (26) illustrated in Schemes 1 and 2. As ex-

Table 2. TMSOTf-activated $\mathrm{Et}_{3} \mathrm{SiH}$-reductive etherification of various $O$-trimethylsilylated sugars at $-78^{\circ} \mathrm{C}$.

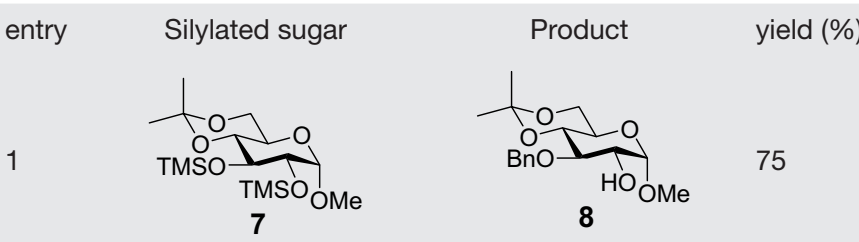

2
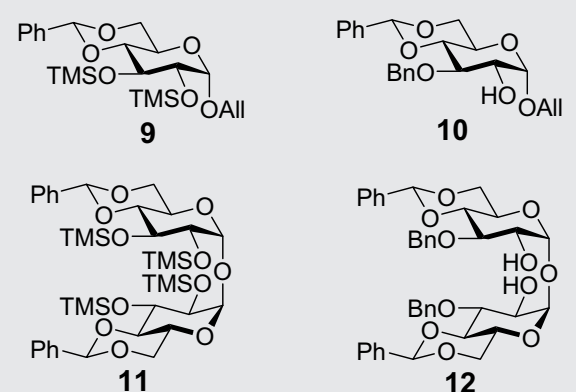

3
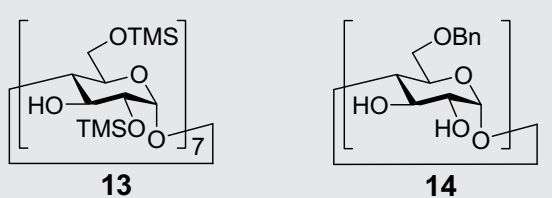

4
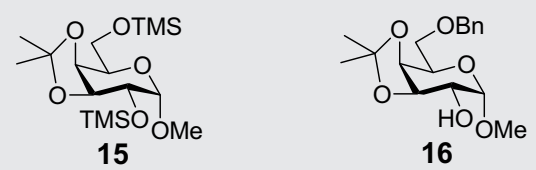

96
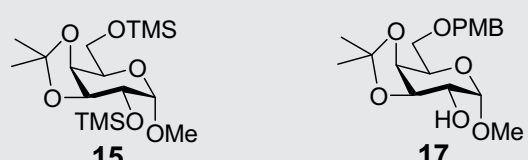

15

17
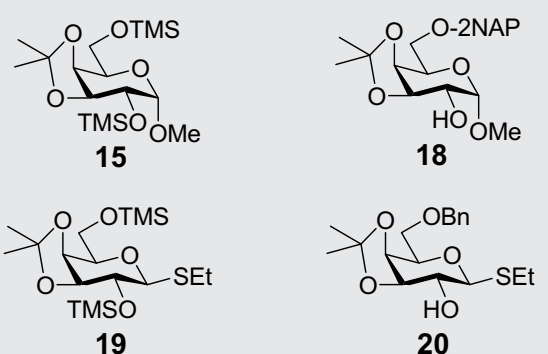

91

20

PMB = para-methoxybenzyl; 2NAP = 2-naphthylmethyl

pected, we successfully obtained the corresponding disaccharide $\alpha-\mathrm{D}-\mathrm{Gal}(1 \rightarrow 2) \mathrm{D}-$ Glc $(\mathbf{2 3}, 61 \%), \alpha-D-M a n(1 \rightarrow 2)$ D-Glc $(\mathbf{2 4}$, $74 \%), \quad \alpha-\mathrm{L}-\mathrm{Fuc}(1 \rightarrow 2) \mathrm{D}-\mathrm{Gal} \quad(27,56 \%)$, $\alpha-\mathrm{D}-\mathrm{Gal}(1 \rightarrow 2) \mathrm{D}-\mathrm{Gal}(\mathbf{2 8}, 55 \%)$ and $\alpha-\mathrm{D}-$ Glc $(1 \rightarrow 2) D-G a l(29,51 \%)$. To the best of our knowledge, this is the first regioselective one-pot protection-glycosylation reaction ever reported.

\section{Regioselective One-pot Protection of Monosaccharides}

Monosaccharide derivatives can be functionalized with orthogonal protective groups by successively adding various reagents in the same pot. For success of such a strategy, judicious selection of protective groups and catalysts must be realized. Benzyl-type ethers offer a wider diversity than other protective groups and can be removed under unique conditions. ${ }^{[23-25]}$ Regarding the catalyst, copper triflate $\left[\mathrm{Cu}(\mathrm{OTf})_{2}\right]$ exhibited the best reactivity among other metal triflates in reductive etherification and was therefore applied in the regioselective benzylation of the bis-TMS compound 30. ${ }^{[26]}$ Unfortunately, the reaction leads to only $72 \%$ yield for the desired $\mathrm{O}(3)$-benzylated product $\mathbf{3 1}$ along with the diol by-product 32 (19\%) (Scheme 3). Using TMSOTf suppressed this problem.

The low solubility of unprotected sugars in common organic solvents, such as 


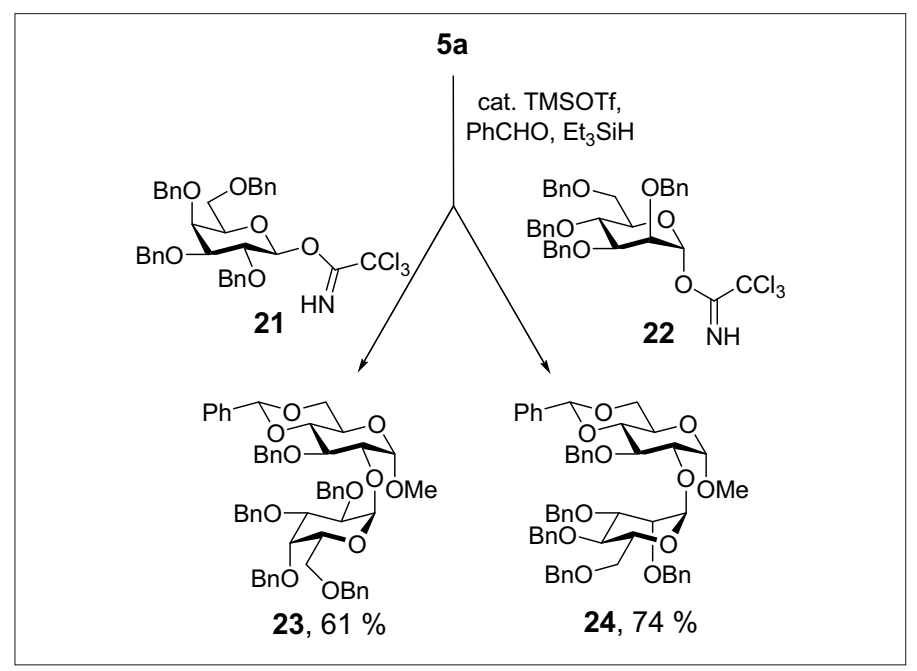

Scheme 1. One-pot regioselective protection and $\mathrm{O}(2)$ $\alpha$-galactosidation and $\alpha$-mannosidation.

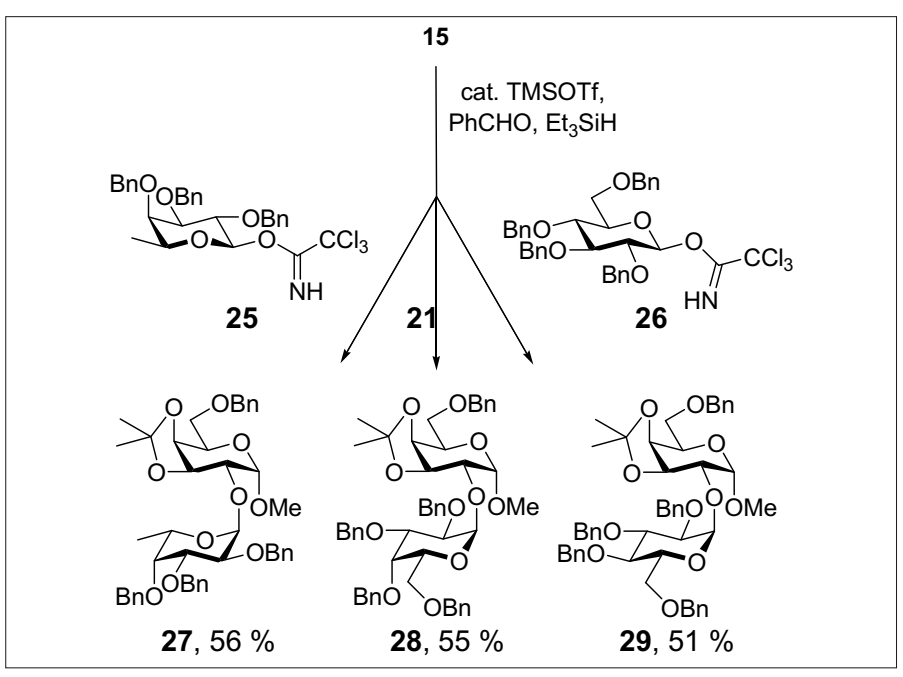

Scheme 2. One-pot regioselective $\mathrm{O}(2) \alpha$-glycosidations.
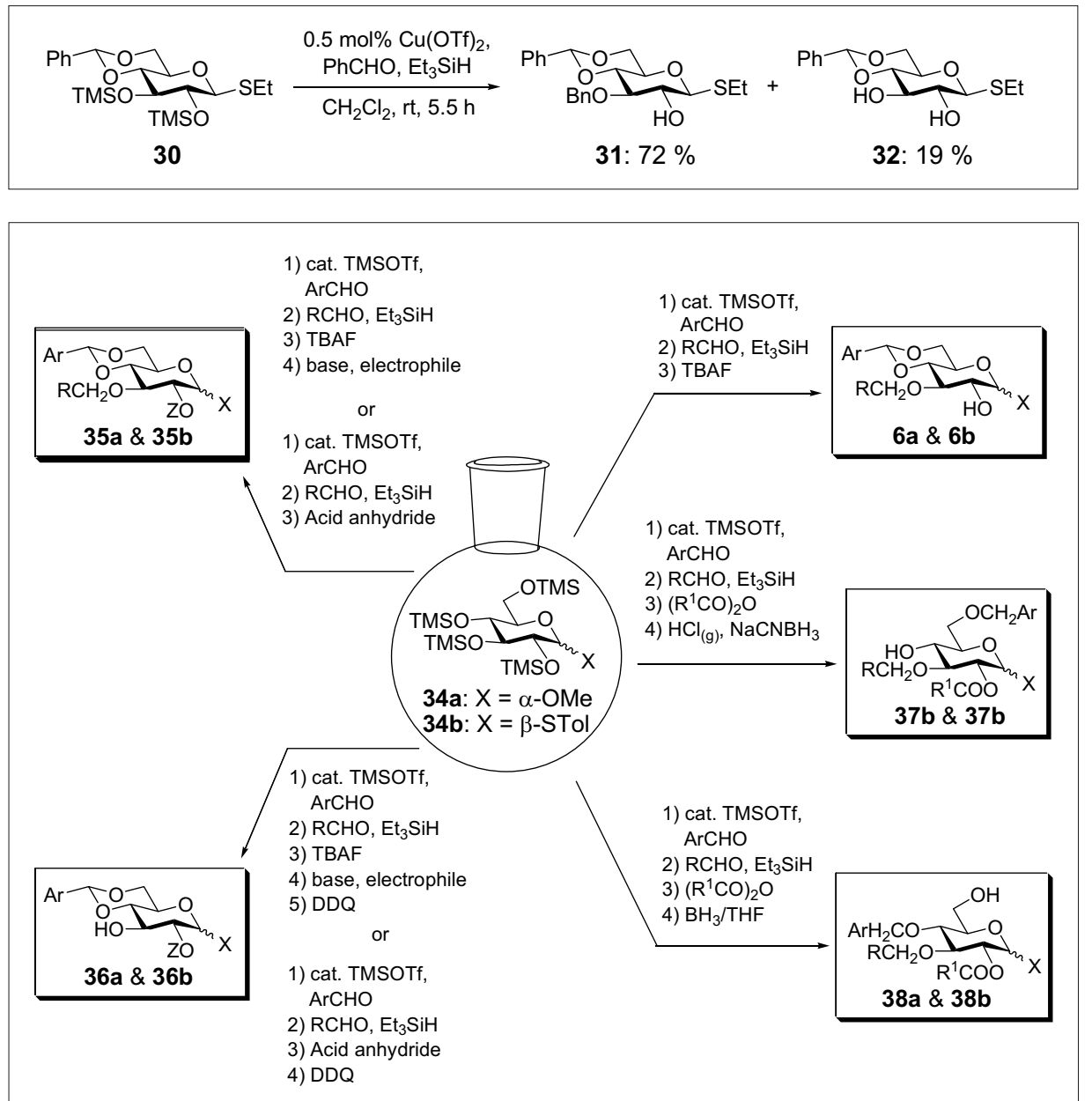

Fig. 2. Combinatorial and regioselective one-pot strategies for the protection and semi-protection of D-glucopyranosides.

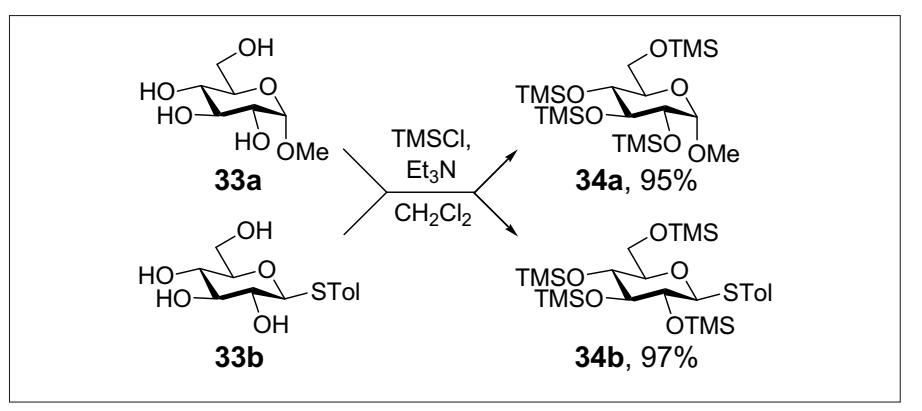

Scheme 3. Regioselective O(3) benzylation.

$\mathrm{CH}_{2} \mathrm{Cl}_{2}$ and toluene, hampered the regioselective modification of the hydroxyl groups. Their transformation into the per-O-TMS derivatives not only provided the functional groups required for the subsequent one-pot protection strategy but also greatly enhanced solubility in organic solvents. Therefore, methyl $\alpha$-D-glucopyranoside 33a and $p$ methylphenyl $\beta$-D-thioglucopyranoside 33b were treated with $\mathrm{TMSCl}$ and $\mathrm{Et}_{3} \mathrm{~N}$ to generate the corresponding per- $O$-TMS ethers 34a and 34b in nearly quantitative yields, respectively (Scheme 4).[27] Our strategy, summarized in Fig. 2, is to regioselectively install combinatorial and orthogonal protective groups throughout the sugar molecule by simply adding various reagents in succession in the same pot. Thus, the per- $O$-silylated sugars bearing an anomeric group $[\mathrm{XR}$, $\mathrm{X}=\mathrm{O}$ or $\mathrm{S}$, where $\mathrm{X}=\mathrm{O}$ can serve as the terminal end of the oligosaccharide, and $\mathrm{X}=$ $\mathrm{S}$ as the elongation unit] can be manipulated to produce either the fully protected monosaccharides 35 or the 2-, 3-, 4-, 6- alcohols 6, 36, 37, 38. ${ }^{[27,28]}$ The novelty of this approach lies in the tuning of the reaction conditions to generate a single regioisomer at each stage using the same catalyst that allows sequential addition of reagents in the same vessel.

\subsection{One-pot Synthesis of \\ 2-Alcohols}

The silylated sugars $\mathbf{3 4 a}$ and $\mathbf{3 4 b}$ were Scheme 4. Persilylation of glucopyranosides. first treated with 1 equivalent of $\mathrm{ArCHO}$ in $\mathrm{CH}_{2} \mathrm{Cl}_{2}$ in the presence of TMSOTf as catalyst at $0{ }^{\circ} \mathrm{C}$ forming the corresponding arylidene acetal at $\mathrm{O}(4), \mathrm{O}(6)$. Then, $\mathrm{Et}_{3} \mathrm{SiH}$ and 1 equivalent of the same or another aryl aldehyde (see Table 1) were added to the mixture cooled to $-86{ }^{\circ} \mathrm{C}$ giving the desired $\mathrm{O}(3)$-ethers. Quenching with stoichiometric amounts of TBAF removed the TMS group at $\mathrm{O}(2)$ giving $\mathbf{6 a}$ and $\mathbf{6 b}$. 


\subsection{One-pot Synthesis of Fully Pro- tected Glycosides}

The first three steps used in the preparations of $\mathbf{6 a}$ and $\mathbf{6 b}$ were repeated, followed by the addition of appropriate electrophiles under basic conditions. This produced the corresponding 35a and 35b in good yields. Accordingly, allyl and various benzyl ethers, as well as esters were introduced at $\mathrm{O}(2)$. For the $\mathrm{O}(2)$-etherifications, allyl bromide, benzyl bromide, 4-methoxybenzyl chloride, 2-naphthylmethyl bromide, 4-chlorobenzyl chloride and 4-bromobenzyl bromide were used as electrophiles and $\mathrm{NaH}$ was employed as base in DMF. For the $\mathrm{O}(2)$ acylations, $\mathrm{Ac}_{2} \mathrm{O}$, chloroacetic anhydride and $\mathrm{BzCl}$ were used as electrophiles and $\mathrm{Et}_{3} \mathrm{~N}$ as base.

Alternative $\mathrm{O}(2)$-acylations could be performed under acidic conditions using TMSOTf.[29,30] Employing carboxylic anhydrides $\left(\mathrm{Bz}_{2} \mathrm{O}\right.$ or $\left.\mathrm{Ac}_{2} \mathrm{O}\right)$, the $\mathrm{O}(2)$-acylated compounds produced under these conditions were identical to those obtained under basic conditions. However, $\mathrm{O}(3)$ PMB ethers could not be made with the latter method as these ethers were cleaved by the anhydrides.

\subsection{One-pot Synthesis of 3-Alcohols}

In the preparation of the fully protected glycosides, PMB or 2-naphthylmethyl (2NAP) could be used as temporary protective groups of $\mathrm{O}(3)$. Thus, the same operations as described for the fully protected glycosides were carried out using anisaldehyde or 2-naphthaldehyde as the second step aldehyde. The subsequent addition of 2,3-dichloro-5,6-dicyano-1,4-benzoquinone (DDQ) provided the corresponding 3-alcohols 36a and 36b that bear alkyl or acyl functionalities at $\mathrm{O}(2)$. It is worth noting that unlike PMB, 2-NAP survived the $\mathrm{O}(2)$ acidic esterification conditions.

\subsection{One-pot Synthesis of 4-Alcohols}

After 4,6-arylidenation, O(3)-arylmethylation, and acidic $\mathrm{O}(2)$ acylation of 34a and 34b, regioselective $\mathrm{O}(4)$ opening of arylidene acetals in the same pot using $\mathrm{HCl}_{(\mathrm{g})} / \mathrm{NaBH}_{3} \mathrm{CN}^{[31]}$ successfully delivered the 4-alcohols $\mathbf{3 7} \mathbf{a}$ and $\mathbf{3 7} \mathbf{b}$, respectively in moderate to good yields. The $\mathrm{O}(2)$-acyl groups remain intact in the presence of $\mathrm{NaBH}_{3} \mathrm{CN}$ and $\mathrm{HCl}$; the yields, however, were only moderate because of partial hydrolysis of the benzylidene acetal brought about by unavoidable reagent moisture. Alternative conditions using $\mathrm{Me}_{2} \mathrm{EtSiH} /$ TMSOTf or $\mathrm{Cu}(\mathrm{OTf})$, are being explored in our group. ${ }^{[32,33]}$

\subsection{One-pot Synthesis of 6-Alcohols}

After 4,6-arylidenation, $\mathrm{O}(3)$-arylmethylation, and acidic $\mathrm{O}(2)$-acylation of 34a and 34b, regioselective $\mathrm{O}(6)$ opening of arylidene acetals in the same vessel us-

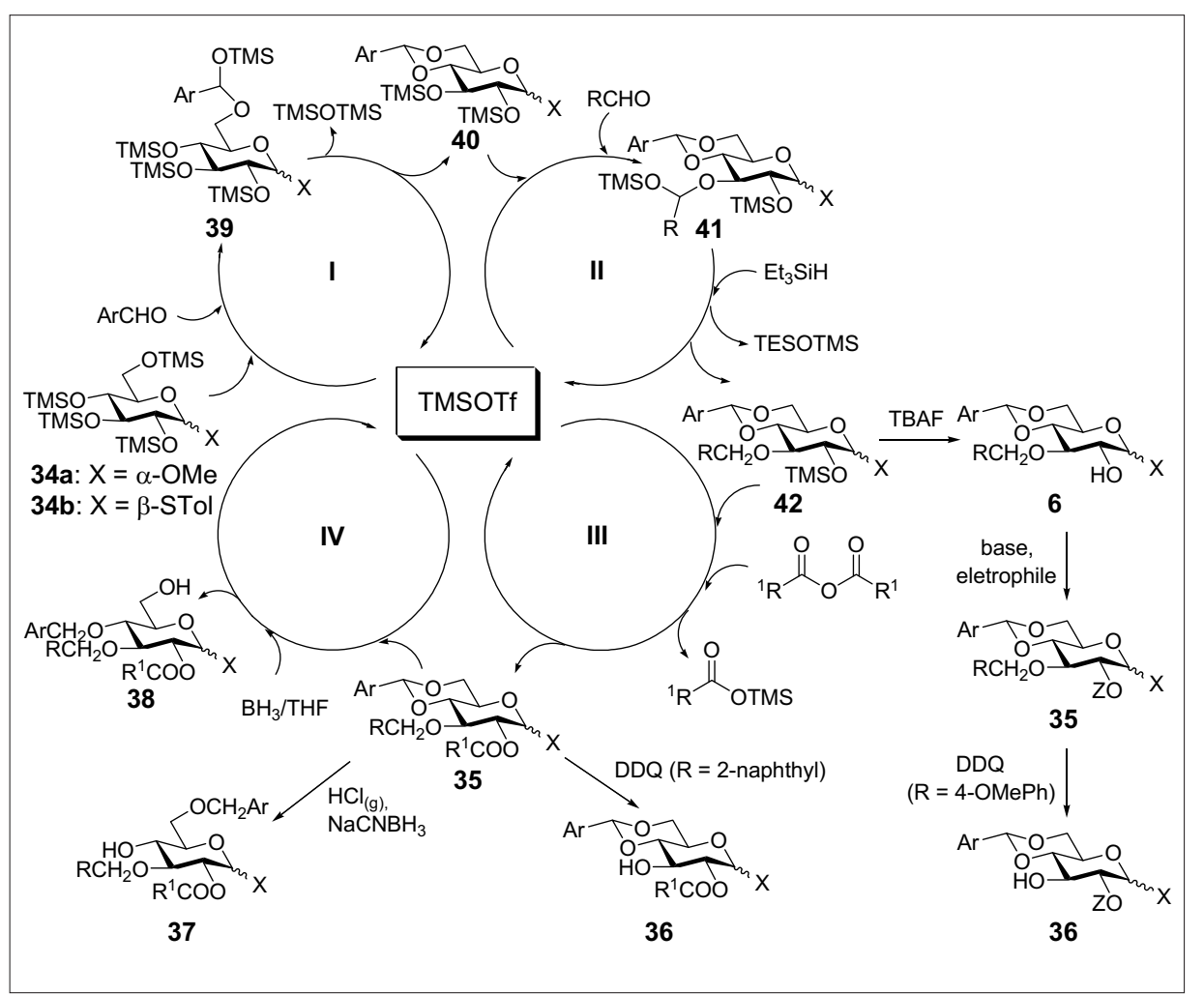

Fig. 3. Proposed mechanism showing the roles of TMSOTf in one-pot protection of D-glucopyranosides.

ing $\mathrm{BH}_{3} / \mathrm{THF}$ as reducing agent catalyzed by TMSOTf ${ }^{[34]}$ at $0{ }^{\circ} \mathrm{C}$ produced 6-alcohols 38a and 38b, respectively.

\subsection{Mechanism}

TMSOTf plays a versatile role as component of multiple catalytic cycles in our one-pot methodology (Fig. 3). In the first catalytic cycle, the reactions of 34a and 34b with aryl aldehyde form TMS-acetals at the most accessible C(6)hydroxyl groups. Due to the proximity of the $\mathrm{O}(4)$-TMS group intermediates, compounds 39 are transformed into the corresponding arylidene acetals $\mathbf{4 0}$ with the release of TMSOTMS (driving force for the reaction). TMSOTf then catalyzes the $\mathrm{Et}_{3} \mathrm{SiH}$-reductive $\mathrm{O}(3)$-etherifications of 40 with a second aryl aldehyde to furnish the corresponding $\mathrm{O}(2)$-TMS ethers $\mathbf{4 2}$ via the intermediacy of TMS-acetals $\mathbf{4 1}$ in the second catalytic cycle. Compounds 42 were quenched with TBAF to provide the 2-alcohols 6, and the exposed hydroxyl can be further modified under basic conditions to yield the fully protected compounds 35. When $\mathrm{R}$ is $\mathrm{PMB}$, further addition of DDQ led to the corresponding 3-alcohols 36. In catalytic cycle III, TMSOTf concomitantly catalyzes the acylation of $\mathbf{4 2}$ with acid anhydride to give the fully protected esters $\mathbf{3 5}$. After acidic esterification, regioselective $\mathrm{O}(3)$-deprotection (when $\mathrm{R}=2$-NAP) using DDQ also afforded the related 3-alcohols 36. Similarly, after completion of catalytic cycle
III, the $\mathrm{O}(4)$ opening of the arylidene by $\mathrm{HCl}_{(\mathrm{N})} / \mathrm{NaCNBH}_{3}$ in the same pot gave 4-alcohols 37. The 4,6-O-arylidene acetal can then be selectively opened at $\mathrm{O}(6)$ by further treatment of esters 35 with $\mathrm{BH}_{3} /$ THF, in the same vessel to afford the corresponding 6-alcohol 38 (catalytic cycle IV).

\subsection{One-pot Protection of Other Monosaccharides}

Although the conditions and strategies here were optimized for D-glucopyranosides, similar approaches can also be applied for the protection of other monosaccharides. Our preliminary studies on the one-pot protections of 2-azido-2-deoxy-D-glucopyranoside, D-mannopyranoside and D-galactopyranoside are depicted in Scheme 5. The silylated 2-azido-2-deoxy-D-glucopyranoside $\mathbf{4 3}$ was benzylidenated using benzaldehyde and catalytic TMSOTf and acylated by acetic anhydride. The concomitant opening of the benzylidene group using $\mathrm{BH}_{3}$ catalyzed by TMSOTf furnished the 6-alcohol 44 in $71 \%$ yield. The 2,3- and 4,6-di-benzylidenation of the silylated mannopyranoside 45 at $0{ }^{\circ} \mathrm{C}$ in $\mathrm{CH}_{3} \mathrm{CN}$ followed by the selective opening of the 2,3-benzylidene using DIBAL-H gave the 2 -alcohol 46 in $70 \%$ yield. The 4,6-benzylidenation and regioselective 4-methoxybenzylation of persilylated isopropyl $\alpha$-D-galactopyranoside $\mathbf{4 7}$ afforded 2-alcohol 48 in $53 \%$ yield. 


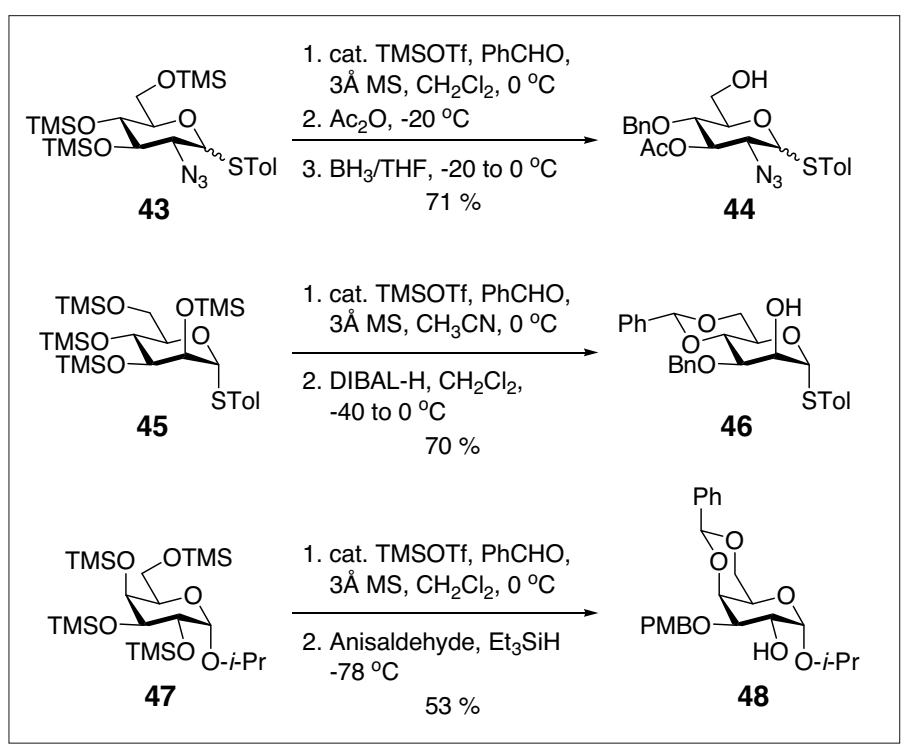

Scheme 5. One-pot preparation of semiprotected pyranosides.
[32] C.-R. Shie, Z.-H. Tzeng, S. S. Kulkarni, B.-J. Uang, C.-Y. Hsu, S.-C. Hung, Angew. Chem. Int. Ed. 2005, 44, 1665 .

[33] C.-R. Shie, Z.-H. Tzeng, C.-C. Wang, S.-C. Hung, J. Chin. Chem. Soc. 2009, 56, 510.

[34] L. Jiang, T. H. Chan, Tetrahedron Lett. 1998, 39,355 .

\section{Conclusion}

We have successfully developed a highly regioselective reductive benzylation of hexopyranosides and demonstrated the first examples of a one-pot sequential protection-glycosylation procedure leading to biologically active $\alpha 1 \rightarrow 2$ linked disaccharides. These results led us to develop a highly efficient and effective methodology to prepare monosaccharide building blocks with combinatorial and orthogonal protective groups in onepot. Per- $O$-trimethylsilylated glucosides were transformed into the fully protected monosaccharides or the 2-, 3-, 4-, 6-alcohols having benzyl-type ethers with additional options for ester or ether type protective groups at the $\mathrm{O}(2)$ position, a key factor for the stereocontrol of the ensuing glycosylation step. Via the TMSOTfcatalyzed reactions, the desired building blocks with various protective groups can be easily produced after a single workup and purification procedure. We, therefore, believe that such a method will greatly expedite and improve the overall synthetic processes of oligosaccharide synthesis.

Received: September 17, 2010

[1] A. Varki, R. D. Cummings, J. D. Esko, H. H Freeze, P. Stanley, C. Bertozzi, G. W. Hart, M. E. Etzler, 'Essentials of Glycobiology', Cold Spring Harbor Laboratory Press, New York, 2009.

[2] B. Ernst, G. W. Hart, P. Sinaÿ, 'Carbohydrates in Chemistry and Biology', Wiley-VCH, Weinheim, 2000, Vol. 1.

[3] C. R. Bertozzi, L. L. Kiessling, Science 2001 , 291, 2357.

[4] L. Schofield, M. C. Hewitt, K. Evans, M.-A. Siomos, P. H. Seeberger, Nature 2002, 418, 785.

[5] H. Yamada, T. Harada, H. Miyazaki, T. Takahashi, Tetrahedron Lett. 1994, 35, 3979.

[6] N. L. Douglas, S. V. Ley, U. Lucking, S. L. Warriner, J. Chem. Soc., Perkin Trans. 1 1998, 51

[7] Z. Zhang, I. R. Ollmann, X.-S. Ye, R. Wischnat, T. Baasov, C.-H. Wong, J. Am. Chem. Soc.
1999, 121,734

[8] P. Sears, C.-H. Wong, Science 2001, 291, 2344.

[9] O. J. Plante, E. R. Palmacci, P. H. Seeberger, Science 2001, 291, 1523.

[10] S. J. Danishefsky, K. F. McClure, J. T. Randolph, R. B. Ruggeri, Science 1993, 260, 1307.

[11] J. H. Kim, H. Yang, J. Park, G.-J. Boons, J. Am. Chem. Soc. 2005, 127, 12090.

[12] S. L. Flitsch, Nature 2005, 437, 201

[13] A. V. Demchenko, Synlett 2003, 1225.

[14] H. Pellissier, Tetrahedron 2005, 61, 2947.

[15] R. R. Schmidt, Angew. Chem. Int. Ed. Engl. 1986, 25, 212.

[16] K. Toshima, K. Tatsuta, Chem. Rev. 1993, 93, 1503.

[17] F. Baressi, O. Hindsgaul, in 'Modern Synthetic Methods', Ed. B. Ernst, C. Leumann, WileyVCH, Switzerland, 1995, p. 281.

[18] P. G. Wang, C. R. Bertozzi, 'Glycochemistry', Marcel Dekker, New York, 2001.

[19] S. Hatakeyama, H. Mori, K. Kitano, H. Yamada, M. Nishizawa, Tetrahedron Lett. 1994, 35, 4367.

[20] C.-C. Wang, J.-C. Lee, S.-Y. Luo, H.-F. Fan, C.-L. Pai, W.-C. Yang, L.-D. Lu, S.-C. Hung, Angew. Chem. Int. Ed. 2002, 41, 2360.

[21] L. Jicsinszky, E. Fenyvesi, H. Hashimoto, A. Ueno, in 'Comprehensive Supramolecular Chemistry', Vol. 3 Ed. J. L. Atwood, J. E. D. Davies, D. D. MacNicol, F. Vogtle, J. Szejtli, T. Osa, Pergamon, Oxford, 1996, p. 57.

[22] B. Fraser-Reid, A. G. Nair, L. G. Nair, K.V. Radhakrishnan, L. J. Cristobal, A. Gomez, C. Uriel, Aust. J. Chem. 2002, 55, 123.

[23] P. J. Kocienski, 'Protecting Groups', Georg Thieme Verlag, Stuttgart, 2005.

[24] T. W. Greene, P. G. M. Wuts, 'Greene's Protective Groups in Organic Synthesis', John Wiley \& Sons, New York, 2007.

[25] S. Hanessian, 'Preparative Carbohydrate Chemistry', Marcel Dekker Inc., New York, 1997.

[26] W.-C. Yang, X.-A. Lu, S. S. Kulkarni, S.-C. Hung, Tetrahedron Lett. 2003, 44, 7837.

[27] C.-C. Wang, S. S. Kulkarni, J.-C. Lee, S.-Y. Luo, S.-C. Hung, Nat. Protoc. 2008, 3, 97.

[28] a) C.-C. Wang, J.-C. Lee, S.-Y. Luo, S. S. Kulkarni, Y.-W. Huang, C.-C. Lee, K.-L. Chang, S.-C. Hung, Nature 2007, 446, 896; b) see also: A. Français, D. Urban, J.-M. Beau, Angew. Chem. Int. Ed. 2007, 46, 8662.

[29] P. A. Procopiou, S. P. D. Baugh, S. S. Flack, G. G. A. Inglis, Chem. Commun. 1996, 2625.

[30] P. A. Procopiou, S. P. D. Baugh, S. S. Flack, G. G. A. Inglis, J. Org. Chem. 1998, 63, 2342.

[31] a) P. J.; Garegg, H. Hultberg, Carbohydr. Res. 1981, 93, C10; b) P. J. Garegg, H. Hultberg, S. Wallin, Carbohydr. Res. 1982, 108, 97. 